\title{
MEDIAN NERVE FORMATION; AN UNUSUAL POSITION IN THE RIGHT UPPER EXTREMITY WITH CLINICAL RELEVANCE.
}

\author{
**NWAFOR Joseph Alo; UCHEWA Obinna Onwe; EGWU Amaobi Jude; and NWAJAGU Godwin Ikechukwu. \\ **Correspondence to Nwafor, Joseph Alo. Department of Anatomy, Faculty of Basic Medical Sciences, \\ College of Medicine, Alex Ekwueme Federal University, Ndufu-Alike, Ikwo (AE-FUNAI). PMB 1010, \\ Ebonyi State, Nigeria. Email: Jnwafor49@gmail.com Tel: +2348134061446
}

\begin{abstract}
There was no direct relationship between its formation and the axillary artery. Hence, it may be not be readily compromised. The site of $\mathrm{MN}$ formation was in proximal relation to the insertion of the coracobrahialis. This is clinically important as it may give a reinforced innervation to the muscle and proprioceptive impulses to medial fibres of the brachialis muscle. Conversely, the MN may be compressed by the tendon of the coracobrahialis, affecting its sympathetic filaments to the brachial artery. Furthermore, when present, it may be severed during reconstructive surgeries around the mid arm as the medial intermuscular septum fades out above the insertion of the coracobrachialis muscle. This report highlights the presence of a significant anatomical variation of the median nerve with regards to its site of formation, roots morphology and distribution, as well as its arterial relations for proper planning of surgeries.
\end{abstract}

Key Words: Median nerve, arterial relations, right upper extremity, Morphology.

\section{INTRODUCTION}

Incidences of variation of the nerves of the brachial plexus have been reported and they appear to be seen in about thirteen (13) per cent of cadavers during routine dissections (Miller et al., 1934; Bergman et al., 1988; Iwamoto et al., 1990; Gümüsburun et al., 2000). The median nerve $(\mathrm{MN})$ is one of the terminal branches of the brachial plexus which is formed by the joining of lateral root, $\mathrm{C} 5-\mathrm{C} 7$ and medial root, C8-T1 (Moore and Dalley, 1999). Median nerve (MN) is one of the nerves that show multiple variations in its formation, communications and distribution. Anatomical variations of the median nerve have been studied and presented by many authors elsewhere (Tahar et al., 2012; Meshram et al., 2012; Bala et al., 2014; Natsis et al., 2016) However, variation with emphasis on its site of formation and its relation to arteries in the arm and axilla in Sub Saharan African countries is relatively sparse.

\section{CASE REPORT}

During our routine undergraduate student dissection using Cunningham's manual of practical Anatomy, an anatomical variation at the site of the median nerve formation was identified and preserved. Photographs were taken, labelled and compared to the normal.

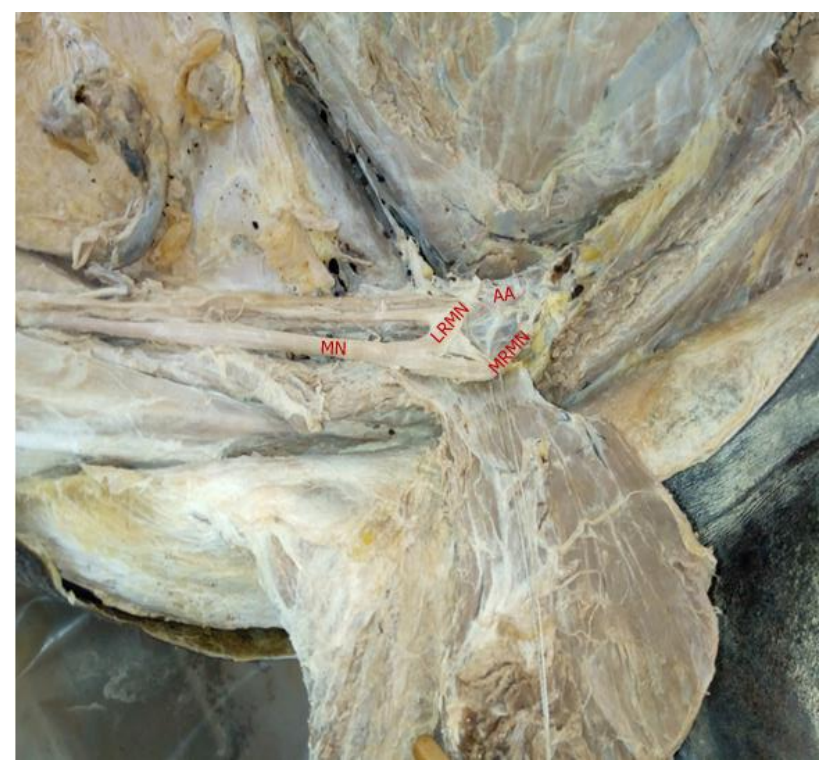

Figures 1: The normal anatomy of the median nerve formation and its relation to the 3rd part of the axillary artery by the union of one lateral and one medial roots. FIGURE 1: $M R \quad M N=$ Median root to median Nerve; $A A=$ Axillary Artery; $L R M N=$ Lateral Root to median Nerve; $\mathrm{MN}=$ Median Nerve 
Anatomy Journal of Africa. 2019. Vol 8 (2): 1577 - 1579.

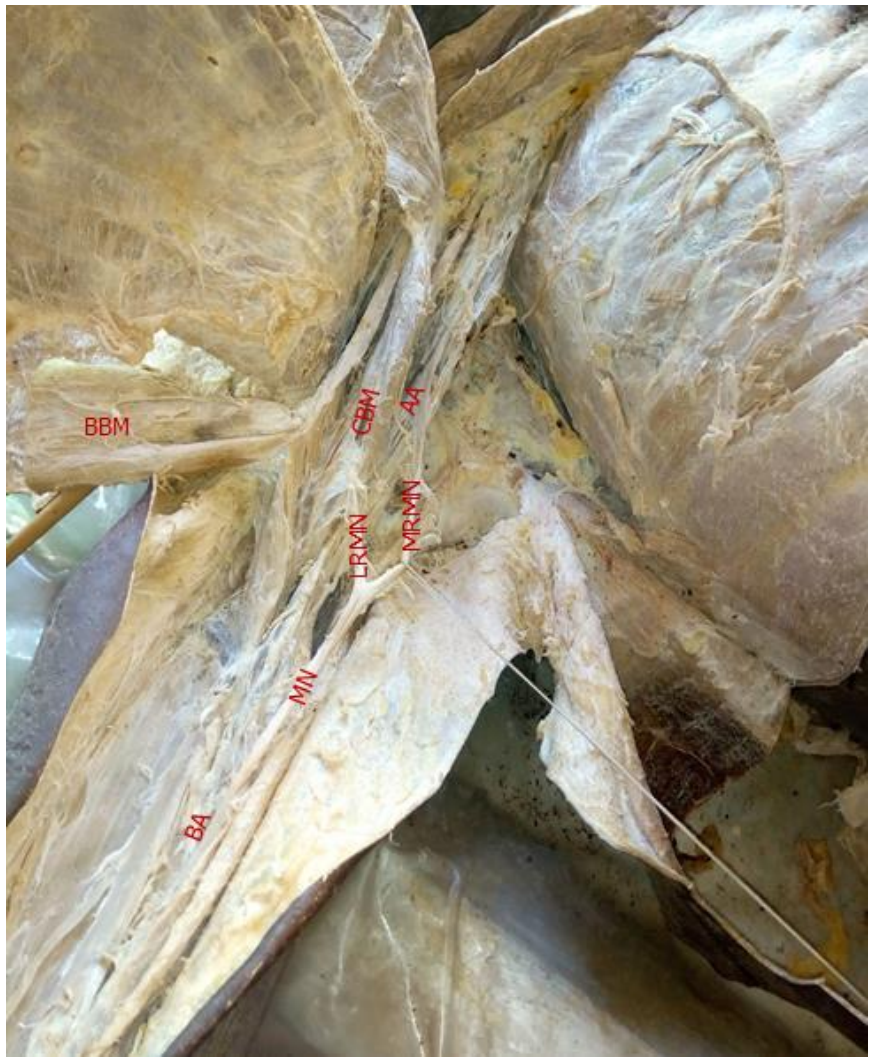

Figure 2: A rare variation in the site of formation of the Median Nerve in the right upper extremities. FIGURE 2: $M N=$ Median Nerve, $M R=$ Medial root of $M N, L R M N=$ Lateral root of $\mathrm{MN}, \mathrm{AA}=$ axillary artery, $\mathrm{BA}=$ Brachial artery, $\mathrm{CBM}=$ Coracobrachialis muscle, $\mathrm{BBM}=$ Biceps brachial muscle (reflected)

\section{DISCUSSION}

Median nerve roots variation is usually divided into two main types. Type I consists of roots with numerical variations while the type II consists of roots with morphological variations (Fazan et al., 2003; Surendran et al., 2013; Patil et al., 2016). Although, we observed no variation in the number of nerve roots that contributed to the formation of the $\mathrm{MN}$, the morphology of the roots varied distinctly. The lateral root is seen to be somewhat shorter than the medial root as it pierces through the coracobrachialis. In this course, it perhaps provide a supply to the muscle and may have a possible connection to the musculocutaneous nerve. There was no relationship between the median nerve formation and the axillary artery. At this position, it lay proximal to the coracobrahialis insertion and the brachial artery in the arm. This is similar to a pattern of arterial relation to the site of $\mathrm{MN}$ formation (Samarawickrama, 2017). It is our belief that this variation quite exist among different populations and the knowledge would provide a surgical guide to these neurovascular structures in the upper limb during reconstructive repairs.

This site is clinically important as it may give a reinforced innervation to the muscle which helps to flex, adduct the arm and stabilize the glenohumeral joint. More so, it may also provide proprioceptive supply to medial fibres of the brachialis muscle which arises from the medial intermuscular septum and thus contribute to define the planes along which nerves and blood vessels travel. Conversely, the MN may be compressed or trapped by the tendon of the coracobrahialis, affecting its sympathetic arterial filaments to the brachial artery as it crosses the artery from the lateral to the medial side. Implicitly, the contractility and functionality of this vessel in blood circulation may be constrained. Furthermore, this nerve may be severed during reconstructive surgeries around the mid arm as the medial intermuscular septum 
fades out above the insertion of the coracobrachialis muscle.
In conclusion, surgeons and other internists should be wary of these anomalies when intervening any procedures around the brachial plexus.

ACKNOWLEDGEMENT: The authors acknowledge the contributions of 2017/2018 batch of undergraduate students and the dissection hall technicians in the Anatomy Department, Federal University Ndufu Alike Ikwo, Ebonyi State, Nigeria

\section{REFERENCES}

1. Bala A, Sinha P, Tamang BK \& Sarda RK. 2014. Anatomical variation: Median nerve formation - A case vignette. J. Clin. Diagn. Res. 8(6):AD03-04.

2. Bergman RA, Thompson SA, Afifi AK, Saadeh FA. 1988. Compendium of Human Anatomic Variation. Munich: Urban \& Schwarzeberg. p. 139-43.

3. Fazan VPS, Amadeu AS, Caleffi AL \& Rodrigues Filho OA. 2003. Brachial plexus variations in its formation and main branches. Acta Cir. Bras. 18(Suppl. 5):14-8.

4. Gümüsburun $E$, Adigüzel E. 2000. A variation of the brachial plexus characterized by the absence of the musculocutaneous nerve: A case report. Surg Radiol Anat. 22:63-5.

5. Iwamoto S, Kimura K, Takahashi Y, Konishi M. 1990. Some aspects of the communicating branch between the musculocutaneous and median nerves in man. Okajimas Folia Anat Jpn. 67:47-52.

6. Meshram SW, Khobragade KJ, Pandit SV \& Jadhav JS. 2012. Four roots of median nerve and its surgical and clinical significance. Int. J. Anat. Var. 5:110-2

7. Miller RA. 1934. Comparative studies upon the morphology and distribution of the brachial plexus. Am J Anat. 54:143-75.

8. Moore KL, Dalley AF. 1999. Clinically oriented anatomy. 6th ed. Philadelphia: Lippincott Williams \& Wilkins.

9. Natsis K, Paraskevas G, Tzika M. 2016. Five roots pattern of median nerve formation. Acta Medica (Hradec Králové), 2016; 59(1):26-8

10. Patil DA, Jadhav, AS, Bhingardeve CV, Katti AS. 2016. Variation in the formation, communication and distribution of median nerve: A cadaveric study. Asian Pac. J. Health Sci. 3(4):17-22

11. Talhar S, Sontakke BR, Bokariya P, Tarnekar AM, Shende MR. 2012. Bilateral variation in formation of the median nerve. IOSR J. Pharm. 2(6):5- 7

12. Samarawickrama MB. 2017. A study of anatomical variations of median nerve formation and its relation to the arteries in the axilla and arm. Int. J. Morphol. 35(2):698-704.

13. Surendran S, Satheesha-Nayak B, Reghunathan D, George BM, Sirasanagandla S 2013. . Three lateral roots of median nerve: A case report. OA Case Rep. 2(10):97 